\title{
A study on the motivation of knowledge spillovers under the influence of high speed railway
}

\author{
Bi Chongren ${ }^{1}$, Zhao Yun ${ }^{2, ~ *}$ \\ ${ }^{1}$ Beijing Jiaotong University, Beijing \\ ${ }^{2}$ China Academy of Transportation Sciences, Beijing \\ *zhaoyun0614@126.com
}

\begin{abstract}
In order to estimate the influence of high speed railway on the knowledge spillovers among different provinces, this paper defines the connotation of knowledge spillovers. According to the analysis framework of knowledge spillover, the SAR/SDM panel data model are established based on the spatial econometric model to analysis the spatial change of knowledge innovation process. The results proved the existence of knowledge spillovers, and analyzed the different motivation of spatial spillover. The main reason for the spatial spillover of knowledge innovation is the path dependence caused by the time lag effect. Based on the analysis of knowledge spillovers in knowledge innovation, it can be found that regional innovation tends to agglomeration under the spillover effect of high speed railway, while regional production tends to be dispersed.
\end{abstract}

Keywords: Knowledge spillovers; high speed railway; spatial econometric model.

\section{Introduction}

The high-speed railway, which has been built and operated, has brought growth to the regional economy and brought new opportunities for the development of regional economy. From the point of view of personal travel, a new type of traffic network, which is formed by high speed railway, can provide more comfortable and fast inter regional commuting, and reduce the overall cost of travel. Travel flow induced by the new traffic facilities, leading residents' activity distribution and density are changed, the individual is engaged in the production and living activities in the larger space, and makes people face-to-face communication opportunities greatly increased.

Under the influence of this kind of mechanism, in the industrial agglomeration theory based on the theory of spatial adjacency knowledge spillover [1], the hypothesis that the spatial distance and the individual interaction opportunity is the reverse relation is no longer established [2]. Because of the high speed railway connection, the regional interaction between the two regions is more frequent than the adjacent space [3]. According to the classification of Fallah and Ibrahim on knowledge spillovers (tacit knowledge spillovers and explicit knowledge spillovers), tacit knowledge spillovers is more dependent on the individual activities, while explicit knowledge spillovers is influenced by individual, enterprise, government policies and other factors [4]. At the 
same time the change of high-speed railway brought on by inter regional knowledge spillovers affect the spatial structure, asymmetric, because knowledge spillovers is an important tool to study the interpretation of spatial agglomeration and economic growth, in the process of high-speed railway impact on social and economic space, knowledge spillovers theory has become an important link of economic evolution of high-speed railway and space.

\section{Motivation analysis}

In the process of innovation and application of knowledge, it is possible to overflow. The positive externality of the input of resources in the region to the production activities of other regions is the spillover effect [5]. In the existing research, knowledge spillover effect has been proved to exist in social production activities. The fundamental cause of knowledge spillovers is that knowledge is non-exclusive, which has a positive or negative impact on the process of innovation and application. Describing the process of knowledge spillovers, the causal path of each knowledge spillover is the direct motivation of knowledge spillovers [6]. According to the process of knowledge innovation, the direct motivation of knowledge spillovers in regional knowledge innovation includes [7]:

(1) Motivation C -- In the process of knowledge innovation, the knowledge stock of the region is not only used in local area, but also can be used in other areas, which has a positive effect on improving knowledge output [8].

(2) Motivation D-- With the externality of shared knowledge stock, the investment of knowledge innovation in an area increases, and the efficiency of knowledge innovation in this region is improved. However, in the case of the same environment, as the role of competition, the efficiency of knowledge innovation in the related areas would be reduced, where the knowledge innovation efficiency is inhibited.

(3) Motivation E-- Due to the particularity of the knowledge innovation, the knowledge innovation input elements of the region have some time lag, which can not be fully reflected in the current knowledge output. However, the innovation input increases the regional innovation ability. In the following period, the efficiency will be embodied in knowledge innovation efficiency. The lag of knowledge input has a negative impact on the output of knowledge in this period, but has a positive impact on the later knowledge innovation.

(4) Motivation G-- The current knowledge output in the region will be accumulated into the regional knowledge stock, which is the input of the next phase of knowledge innovation. It makes the knowledge innovation of each region become a continuous process. The increase of current knowledge output has a positive impact on the next phase of knowledge innovation.

\section{Spatial econometric model of Knowledge spillovers}

For the area of knowledge output data, due to the presence of dependencies between $\mathrm{N}$ observations or regions, Ord presents a simplified parameter description of the dependencies between regions. Furthermore, the spatial autoregressive data generation 
process is constructed, which can be expressed as the observation value of the variable y:

$$
y_{i}=\rho \sum_{j=1}^{n} W_{i j} y_{j}+\varepsilon_{i}, \quad \varepsilon_{i} \sim N\left(0, \sigma^{2}\right) \mathrm{i}=1, \ldots, \mathrm{n}
$$

In the formula, $\rho$ is the influence of spatial factors on knowledge innovation Y. The value vector of variable $y$ is hypothesised that the form of deviation from the mean should be used to exclude the intercept. The $W_{i j} y_{j}$ in the formula is called the spatial lag term, a linear combination of the observed values of the variable $y$, which represents spatial dependence of knowledge output. There is a relationship between the observed value and the observed value of another location, which can be interpreted as three kinds of interaction effects: the endogenous interaction effect, the exogenous interaction effect and the interaction effect of the error term. The endogenous interaction effect, in the spatial econometric model, can be expressed as:

$$
\vec{Y}=\delta W \vec{Y}+\alpha I_{n}+X \vec{\beta}+\vec{\varepsilon}
$$

In the exogenous interaction effect, the explanatory variable of a specific unit depends on the independent explanatory variables of other units. The expression of this model is:

$$
\vec{Y}=\alpha I_{n}+X \vec{\beta}+W X \vec{\theta}+\vec{\varepsilon}
$$

In the interaction effect between the errors terms, the determinants of the missing explanatory variables are spatially correlated, which are subject to spatial interaction. The interaction effect between the error terms can also be interpreted as a correction mechanism, such as the correction mechanism of the enterprise's unpredictable policy change, and the expression of the error item interaction effect model is as follows:

$$
\begin{gathered}
Y=\alpha I_{n}+X \vec{\beta}+\vec{u} \\
\vec{u}=\lambda W \vec{u}+\vec{\varepsilon}
\end{gathered}
$$

The three models are called--spatial error model (SEM), spatial autoregressive model (SAR), spatial durbin model (SDM). According to the characteristics of the relationship between the sample and the variables, a reasonable measurement model is selected to measure the spatial effect of knowledge spillovers.

\section{Results Analysis}

\begin{tabular}{|c|c|c|c|c|c|c|}
\hline Variable & $\begin{array}{c}\text { Random } \\
\text { effects SAR } \\
\text { model }\end{array}$ & $\mathrm{t}$ & $\begin{array}{c}\text { Random } \\
\text { effects SDM } \\
\text { model }\end{array}$ & $\mathrm{t}$ & $\begin{array}{l}\text { Time fixed } \\
\text { effect SAR } \\
\text { model }\end{array}$ & $\mathrm{t}$ \\
\hline intercept & 1.685999 & 6.078107 & 0.037949 & 0.088476 & & \\
\hline loghum & 0.178306 & 5.758845 & 0.131528 & 4.749864 & 0.110837 & 3.724465 \\
\hline
\end{tabular}

Based on the Euclidean distance weight matrix, the knowledge spillovers in the process of knowledge innovation in the provinces of China in 2005-2014 were analyzed. The results are as follows:

Table 1 2005-2009 knowledge innovation panel data analysis results 
Table 1, cont.

\begin{tabular}{|c|c|c|c|c|c|c|}
\hline logpat & 0.795629 & 34.22702 & 0.830392 & 40.05689 & 0.847944 & 37.95541 \\
\hline $\mathrm{W}^{*} \operatorname{loghum}$ & & & 0.120069 & 1.655626 & & \\
\hline $\mathrm{W}^{*} \log$ at & & & -0.539 & -5.80637 & & \\
\hline $\mathrm{W}^{*}$ dep.var. & -0.05567 & -2.07906 & 0.469301 & 4.177615 & 0.051297 & 1.631601 \\
\hline $\operatorname{sigma}^{\wedge} 2$ & 0.0169 & & 0.0129 & & 0.0135 & \\
\hline log-likelihood & 89.90988 & & 107.6191 & & 109.06848 & \\
\hline R-squared & 0.9892 & & 0.9918 & & 0.9917 & \\
\hline Direct Coefficient & 0.7961 & 34.4875 & 0.8212 & 40.2592 & 0.8483 & 37.6827 \\
\hline Indirect Coefficient & -0.0427 & -2.2297 & -0.2749 & -2.8494 & 0.0471 & 1.5028 \\
\hline total Coefficient & 0.7534 & 26.8194 & 0.5463 & 5.331 & 0.8955 & 20.7194 \\
\hline \multicolumn{7}{|c|}{ Table 2 2010-2014 knowledge innovation panel data analysis results } \\
\hline \multicolumn{3}{|c|}{ Random effects } & \multicolumn{2}{|l|}{ Random effects } & \multicolumn{2}{|l|}{ Time fixed effect } \\
\hline Variable & SAR model & $\mathrm{t}$ & SDM model & $\mathrm{t}$ & SAR model & $\mathrm{t}$ \\
\hline intercept & -0.19229 & -0.58026 & 0.589911 & 1.167557 & & \\
\hline loghum & 0.162144 & 3.971211 & 0.195659 & 4.910958 & 0.212703 & 5.607185 \\
\hline logpat & 0.845113 & 27.45715 & 0.82298 & 27.69168 & 0.808475 & 28.26426 \\
\hline $\mathrm{W} * \operatorname{loghum}$ & & & -0.20981 & -2.46089 & & \\
\hline $\mathrm{W}^{*}$ logpat & & & -0.38451 & -3.64651 & & \\
\hline $\mathrm{W}^{*}$ dep.var. & 0.096289 & 3.546395 & 0.569306 & 5.642974 & -0.01962 & -0.64906 \\
\hline $\operatorname{sigma}^{\wedge} 2$ & 0.021 & & 0.0174 & & 0.0167 & \\
\hline log-likelihood & 74.39735 & & 84.92962 & & 93.63991 & \\
\hline $\begin{array}{c}\text { R-squared } \\
\text { Direct }\end{array}$ & 0.9892 & & 0.9911 & & 0.9917 & \\
\hline $\begin{array}{c}\text { Coefficient } \\
\text { Indirect }\end{array}$ & 0.8465 & 27.3402 & 0.8303 & 28.2667 & 0.8079 & 29.1069 \\
\hline $\begin{array}{c}\text { Coefficient } \\
\text { total }\end{array}$ & 0.0913 & 3.2414 & 0.1906 & 1.5454 & -0.0163 & -0.7261 \\
\hline Coefficient & 0.9379 & 21.6597 & 1.0209 & 7.7791 & 0.7916 & 21.3642 \\
\hline
\end{tabular}

By comparing Table 1 with Table 2, the results of the regression of knowledge innovation production reflect the change of knowledge spillovers from 2005-2009 to 2010-2014. In the process of knowledge innovation, the stock of knowledge spillover is weakened, while the labor spillover effect increases. The spillover effect of knowledge innovation output becomes less, which shows that the innovation industry between regions tends to be more specialized, and the spillover effect of knowledge stock for knowledge innovation in the surrounding region is weakened.

\section{5 conclusions}

According to the results of spatial econometric analysis, it is found that the knowledge spillovers between different regions has changed since the emergence of high-speed railway, while the spatial spillover has remained unchanged. Compared with the regression coefficient of the two periods 2005-2009/2010-2014, it can be found that in the direct cause of the knowledge spillovers: the motivation of $G$ is enhanced, the 
motivation $\mathrm{C}$ and the motivation of $\mathrm{E}$ are weakened. The regression results show that the motivation of knowledge spillovers have changed from knowledge application to knowledge innovation.

\section{Reference}

[1] Ibrahim S E, Hosein F M, Reilly R R. Do Localized Clusters Influence Creativity of Inventors? Creativity \& Innovation Management, 2006, 15(4):410-418.

[2] Samaniego R M. Knowledge spillovers and intellectual property rights. International Journal of Industrial Organization, 2013, 31(1):50-63.

[3] Steen M, Hansen G H. Same Sea, Different Ponds: Cross-Sectorial Knowledge Spillovers in the North Sea[J]. European Planning Studies, 2014, 22(10):20302049.

[4] Glaeser E L, Saiz A. The Rise of the Skilled City. Brookings-Wharton Papers on Urban Affairs, 2003, (35):47-105.

[5] Henderson J V, Wang H G. Urbanization and city growth: The role of institutions. Regional Science \& Urban Economics, 2007, 37(3):283-313.

[6] Kalapouti K, Varsakelis N C. Intra and inter: regional knowledge spillovers in European Union[J]. The Journal of Technology Transfer, 2015, 40(5):1-22.

[7] Anselin L, Bera A K, Florax R, et al. Simple diagnostic tests for spatial dependence. Regional Science \& Urban Economics, 2012, 26(1):77-104.

[8] Anselin L, Rey S J. Perspectives on Spatial Data Analysis. Advances in Spatial Science, 2010, 50(1):1-20. 